\title{
ENTRE A VEGETAÇÃO E O CONCRETO: UMA ANÁLISE DA ARBORIZAÇÃO URBANA NAS PRAÇAS DO MUNICÍPIO DE CASTANHAL, PA
}

\author{
BETWEEN VEGETATION AND CONCRETE: AN ANALYSIS OF URBAN FORESTS \\ IN SQUARES IN THE CITY OF CASTANHAL, PA
}

\author{
Larisse Medeiros Gonçalves \\ Luana Santos dos Santos \\ Pedro Henrique da Silva \\ Louise Ferreira Rosal
}

\section{Resumo}

A arborização urbana é importante para sustentabilidade e qualidade de vida de uma região, sendo que sua implementação requer planejamento criterioso. O objetivo dessa pesquisa foi diagnosticar, por meio de um inventário florestal, a silvicultura urbana presente nas praças do município de Castanhal, PA. Foi realizado um inventário da vegetação arbórea a partir de exsicatas. Calculou-se a frequência absoluta e a frequência relativa, classificando em nativas e exóticas. Foram encontradas 11 diferentes espécies distribuídas em 8 famílias botânicas, com 27,27\% de nativas do país e 72,73\% exóticas, provindas da Asia (75\%), América Central (12,5\%) e África (12,5\%). A Mangifera indica L. (34,7\%) e o Ficus benjamina L. $(22,7 \%)$ apresentaram maior incidência, com mais de $50 \%$ do total de espécies. Concluiu-se que a arborização estudada está aquém dos padrões estabelecidos, necessitando de elementos de biodiversidade nativa funcional.

Palavras-Chaves: Áreas verdes. Florestas Urbanas. Sustentabilidade. Biodiversidade nativa.

\section{Abstract}

Urban forest is important for sustainability and quality of life in a region, its implementation requires careful planning. This research aimed to diagnose, through a forest inventory, the urban forestry present in the squares of the city Castanhal, PA. An inventory of the arboreal vegetation was carried out from exsiccates. The absolute frequency and the relative frequency were calculated, classifying as native and exotic. We found 11 different species distributed in 8 botanical families, with $27.27 \%$ native to the country and $72.73 \%$ exotic, from Asia (75\%), Central America (12.5\%), and Africa (12.5\%). Mangifera indica L. (34.7\%) and Ficus benjamina L. (22.7\%) presented a higher incidence, with more than $50 \%$ of the total species. It was concluded that the afforestation studied is below the established standards, requiring elements of functional native biodiversity

key-words: Green areas. Urban Forests. Sustainability. Native Biodiversity. 


\section{INTRODUÇÃO}

Os centros urbanos comportam cerca da metade da população mundial e estima-se que esse valor pode aumentar para $66 \%$ até o ano de 2050 (FAO, 2016). Na América Latina, estima-se que $80 \%$ da população vive em cidades, é previsto que esse percentual alcance $90 \%$ até 2025 (CBD, 2012). Sabe-se que a maior parte desse crescimento ocorre de forma desenfreada e sem planejamento base para a qualidade de vida da população, assim, tem-se na Arborização Urbana (AU) um dos meios essenciais para a sustentabilidade e o bem-estar de uma região, pois está diretamente relacionada a pautas ambientais, sociais e econômicas.

Antes de ressaltar os benefícios da $A U$, é importante trazer uma breve abordagem sobre a definição dessa expressão. A Arborização Urbana foi inicialmente empregada no Brasil em tradução ao termo Urban Forest, em vista de muitos pesquisadores norte -americanos o utilizarem. Contudo, a AU também passou a ser usada no Brasil como sinônimo de arboricultura, designando o ato ou ação de plantar árvores em ambientes urbanos. Também é conhecida como áreas verdes urbanas ou silvicultura urbana (DUARTE et al., 2018).

Para Sirvinskas (2000, p. 270) "a arborização urbana é plantar ou resguardar árvores espontâneas que integram o meio ambiente natural ou implantado que, por sua vez, faz parte do patrimônio de um determinado espaço". Outra definição de florestas urbanas é dada pela inclusão de todas as árvores na área urbana, em cidades, vilas e subúrbios, incluindo árvores em terras públicas e privadas, em ruas individuais e grupos de árvores de parque ou jardins, bem como fragmentos de florestas periurbanas que se estendem às áreas metropolitanas externas, de modo geral, quaisquer outros espaços verdes com árvores, como corredores ripários, telhados e viveiros (GALLO; GUARALDO, 2017; ENDRENY et al., 2018; ROMAN et al., 2018; HAN et al., 2021).

A AU possui atuação funcional em serviços ambientais, Zhi-Ying e Yeo-Chang (2021) subdividem esses benefícios em: serviços de provisão (como a disponibilidade de algumas frutas), serviços reguladores (como a minimização de ilhas de calor urbanas, inunda- ções, poluição do ar, contaminação do solo), serviços de habitat (ou de apoio) e serviços socioculturais. Outros estudos apontam que a Urban Forest promove maior sombreamento, resfriamento, atenuação de ruídos, além de compor a estética local e atrair biodiversidade animal, fortalecendo os microecossistemas nos centros urbanos. As questões benéficas que estão conectadas ao social são referentes ao lazer, à cultura e ao patrimônio arquitetônico, a estética desses ambientes pode ajudar a fomentar o turismo ligado ao âmbito do desenvolvimento econômico (GONÇALVES et al., 2018; LOURDES et al., 2021; HAN et al., 2021).

Nascimento e Shandas (2021, p. 49) afirmam que "estradas, edifícios, renovação urbana, infraestrutura verde e novos empreendimentos competem pelo espaço urbano limitado". Por isso, necessita-se de formulações estratégicas a fim de harmonizar infraestruturas cinzentas com áreas verdes. A implantação da AU não pode ser feita de maneira aleatória, pois demanda um planejamento criterioso, compilando manejos adequados com a escolha de espécies (priorizando a biodiversidade nativa) (BANERJEE; DEWANJI, 2017; ZHI-YING; YEO-CHANG, 2021).

Embora os benefícios da AU estejam difundidos em algumas cidades do Brasil, muitos municípios ainda possuem carência de projetos mais minuciosos, comprometidos com os principais objetivos desses espaços. Gonçalves et al. (2018, p. 131) comentam que as praças devem contemplar atributos indispensáveis, tais como, "árvores com flores bonitas e visíveis; tronco reto e copa bem formada para valorização estética das cidades", para além desses pontos, áreas verdes devem ser distribuídas a fim de fornecer seus benefícios de forma homogênea para todos os bairros de um município.

Cidades como Castanhal possuem ambientes intensamente alterados, devido aos modelos de edificações contemporâneos e loteamento do solo, que restringem os espaços destinados às áreas verdes. Essas restrições limitam a utilização de árvores na floresta urbana, em relação ao seu porte e à quantidade de espécies. Salienta-se que os espaços verdes públicos gerenciam a conectividade ecológica, integrando a infraestrutura biofísica e disponibilizando multifuncionalidades para a qualidade de vida (MADUREIRA, 2012). 
Paralelamente, há uma preocupação de estudiosos e planejadores civis para que haja preservação, recuperação e criação de superfícies verdes urbanas, como as praças, posto que tais espaços são fundamentais para a qualidade ambiental e de vida da população (LACY; SHACKLETON, 2017).

Este estudo traz importantes contribuições sobre planejamento de arborização urbana e gerenciamento municipal dos espaços públicos, distribuição de áreas verdes, adequação de espécies e o potencial dos indivíduos que compõem a AU do local de estudo. Com isso, o objetivo dessa pesquisa foi diagnosticar, por meio de um inventário florestal, a silvicultura presente nas praças do perímetro urbano do município de Castanhal, PA.

\section{Metodologia}

O estudo se deu no município de Castanhal (PA), no nordeste paraense, situado à aproximadamente $70 \mathrm{~km}$ da capital. 0 município se localiza a uma latitude $01^{\circ} 17^{\prime} 49^{\prime \prime}$ Sul e a uma longitude $47^{\circ}$ 55' 19" Oeste, com altitude de 41 metros. Possui uma área de $1.029,191 \mathrm{~km}^{2}$ (Figura 1). Castanhal apresenta população urbana estimada de 212.203 (IBGE, 2020). Os procedimentos foram realizados no perímetro urbano da cidade, composto por 17 praças públicas inventariadas neste estudo. $O$ reconhecimento e georreferenciamento das praças públicas foram feitos com GPS de navegação, modelo Garmin Map $62 \mathrm{sc}^{\circledR}$. Com a planta baixa da cidade, adquirida na Secretaria Municipal de Obras (SEMOB) e auxílio do
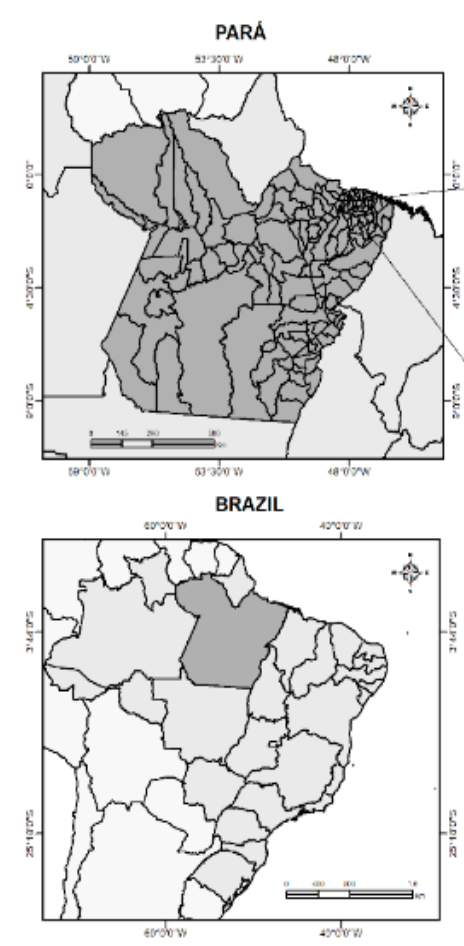

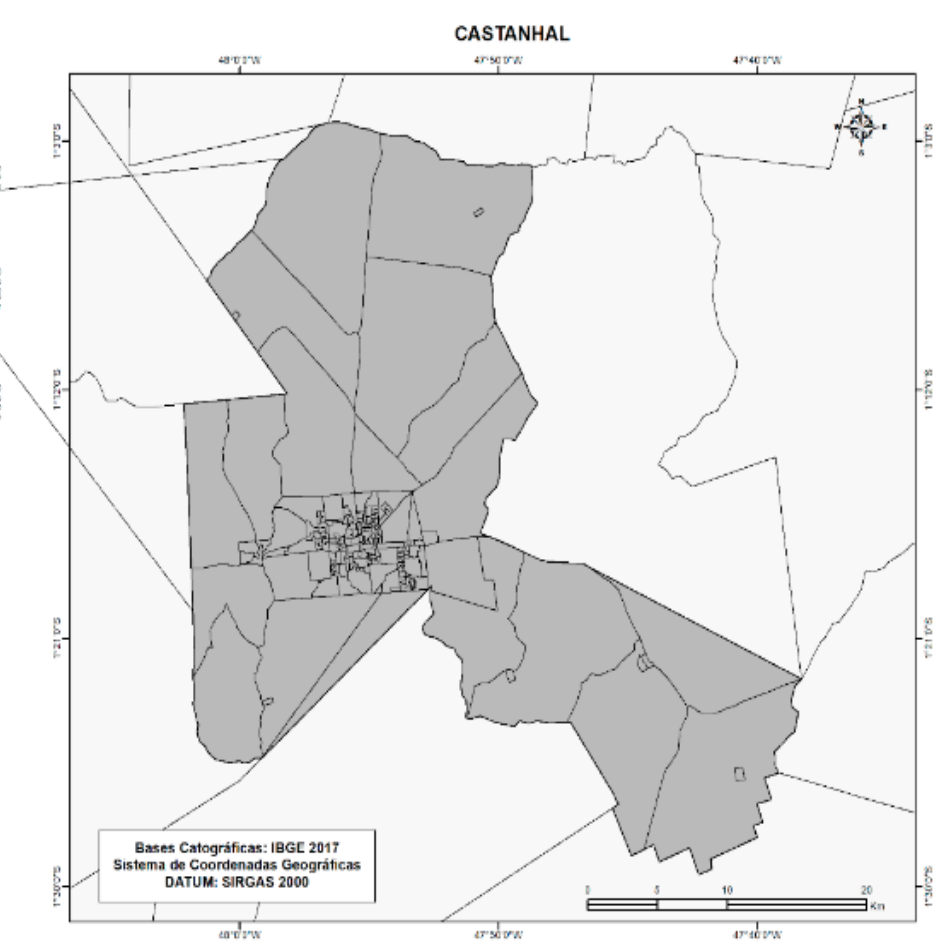

Figura 1 - Mapa de localização do município de Castanhal.

Fonte: Mapa produzido no Software Qgis, por Pedro Monteiro, 2020. 
programa AutoCAD ${ }^{\circledR}$, foi possível a identificação das praças públicas do município (apenas da área urbana) (Figura 2). Foram realizados registros fotográficos das praças.

As coletas para o inventário foram feitas no mês de abril de 2016 . Foram amostrados os indivíduos com circunferência na altura do peito (CAP) maior ou igual a $10 \mathrm{~cm}$ e altura acima de $1,30 \mathrm{~m}$. A identificação das espécies foi realizada de acordo com a metodologia proposta por Martins-da-Silva (2002).

Uma vez coletadas, as amostras foram prensadas e secas em estufa com circulação forçada de ar a $65^{\circ} \mathrm{C}$ por três dias, no Laboratório de Solos do IFPA - Campus Castanhal. Posteriormente, foram encaminhadas para o Laboratório de Botânica da EMBRAPA Ama- zônia Oriental e a identificação se deu por profissionais parabotânicos. Os meios utilizados para a identificação das espécies foram: comparação com exsicatas do acervo do laboratório do Instituto Agronômico do Norte (IAN); classificação dos gêneros em famílias segundo o Angiosperm Phylogeny Group III (APG III) e conferência na lista de espécies da flora do Brasil.

Para a análise da representatividade das espécies amostradas, calculou-se a frequência absoluta (FA) e a frequência relativa (FR) de cada espécie encontrada, conforme Brianezi et al. (2013). A frequência absoluta consiste no somatório do número ( $\mathrm{n}$ ) de indivíduos de uma determinada espécie (i) e a frequência relativa refere-se ao percentual que cada espécie (i) representa em relação ao total de espécies amostradas (equação 1).

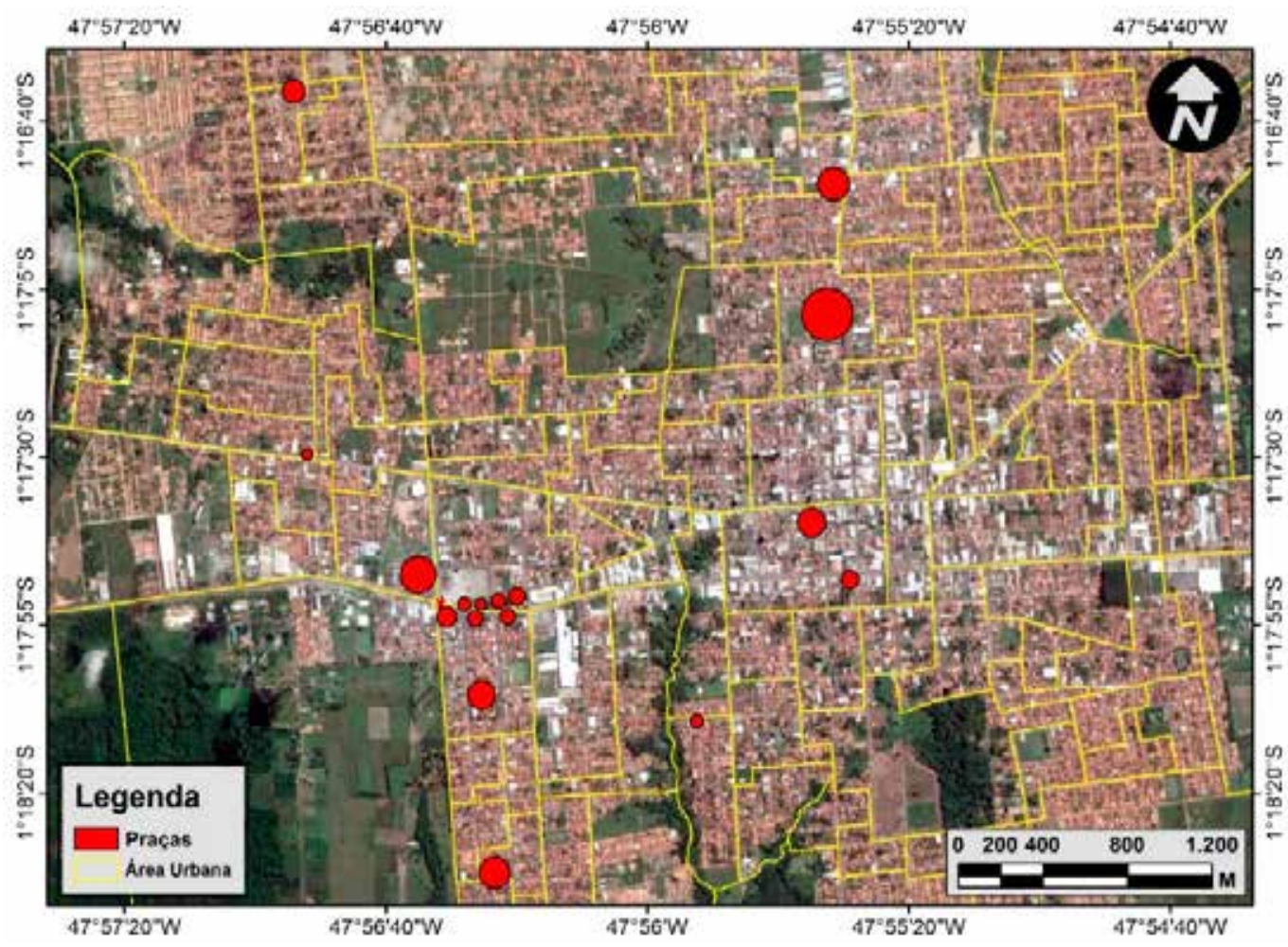

Figura 2 - Delimitação da área urbana, com indicação das praças estudadas por pontos vermelhos.

Fonte: Mapa produzido no Software Qgis, por Pedro Monteiro, 2020 


$$
\mathrm{FR}_{\mathrm{i}}=(\mathrm{n} / \mathrm{N}) * 100(1)
$$

em que:

$\mathrm{FR}_{\mathrm{i}}=$ frequência relativa do número de árvores, em porcentagem;

ni = número de indivíduos da espécie i;

$\mathrm{N}=$ número total de indivíduos.

Para analisar as funcionalidades das espécies encontradas nas praças, levando em consideração a adequação para cada ambiente e o potencial desses indivíduos para a arborização, utilizou-se o Manual de Arborização Urbana de Belém (PORTO; BRASIL, 2013). Adicionalmente, foram averiguados os centros de origem dos exemplares amostrados utilizando literatura especializada como em Lorenzi (2002 e 2013) e Lorenzi e Souza (2001).

Para contextualizar a discussão acerca da representatividade das espécies e fomentar a discussão, obteve-se um aporte teórico por meio da busca em bases de dados como Google Scholar ${ }^{\circledR}$, Sciencedirect ${ }^{\circledR}$, Springer $\AA^{\circledR}$ e Scopus $\AA$. Adotou-se como critério de exclusão e inclusão: autores que são referência da área, notas técnicas de instituições do ramo e materiais atuais publicados em periódicos reconhecidos.

\section{Resultados e Discussão}

Com base nos dados coletados na etapa de campo e no laudo de identificação botânica, foi possível elencar a quantidade de espécies presentes nos espaços, compreender as suas funcionalidades nas diversas praças, avaliar a adequação para cada ambiente e compreender o potencial de cada um desses indivíduos para a arborização.

Foram encontradas 11 espécies arbóreas distribuídas em 8 famílias botânicas (FB) (Tabela 1). Durante o reconhecimento e levantamento nas 17 praças, constatou-se que em $88,2 \%$ havia algum elemento arbóreo com as especificidades assumidas neste estudo - CAP

Tabela 1 - Espécies arbóreas de indivíduos encontrados nas praças públicas de Castanhal.

\begin{tabular}{|c|c|c|c|c|c|}
\hline Nome científico & Nome popular & Família & FA & FR (\%) & Origem \\
\hline Licania tomentosa (Benth.) Fritsch & Oiti & Chrysobalanaceae & 10 & 3,25 & $\mathrm{n}$ \\
\hline Tabebuia roseoalba (Ridl.) Sandwith & Ipê-branco & Bignoniaceae & 20 & 6,49 & $\mathrm{n}$ \\
\hline Handroanthus heptaphyllus (Vell.) Mattos & Ipê-roxo, pau-d'arco. & Bignoniaceae & 25 & 8,12 & $\mathrm{n}$ \\
\hline Bauhinia monandra Kurz & Pata-de-vaca & Leguminosae-Caesalpinioideae & 15 & 4,87 & e \\
\hline Senna siamea (Lam.) H.S. Irwin \& Barneby & Cássia-de-sião & Leguminosae-Caesalpinioideae & 3 & 0,97 & e \\
\hline Ficus benjamina $\mathrm{L}$. & Ficus & Moraceae & 70 & 22,73 & e \\
\hline Mangifera indica L. & Mangueira & Anacardiaceae & 107 & 34,74 & e \\
\hline Roystonea oleracea (Jacq.) O.F. Cook & Palmeira Imperial & Arecaceae & 46 & 14,94 & e \\
\hline Elaeis guineensis Jacq. & Dendê & Arecaceae & 9 & 2,92 & e \\
\hline Syzygium malaccense (L.) M. Perry. & Jambeiro & Myrtaceae & 1 & 0,32 & e \\
\hline \multirow[t]{2}{*}{ Terminalia catappa Linn. } & Castanhola & Combretaceae & 2 & 0,65 & $\mathrm{e}$ \\
\hline & Total & & 308 & $100 \%$ & - \\
\hline
\end{tabular}

Fonte: Elaborado pelos autores (2017). Legenda: *FA - frequência absoluta; **FR (\%) - frequência relativa; *** $\mathrm{n}-\mathrm{nativas;}{ }^{* * * *} \mathrm{e}-$ exóticas. 
$\geq$ a $10 \mathrm{~cm}$ e acima de $1,30 \mathrm{~m}$ de altura - e em $11,7 \%$ inexistiam árvores (Figura 3). É válido destacar que a quantidade de espécies encontradas é insuficiente quando se projeta esse quantitativo para o grande número de praças amostradas, demonstrando que existe uma falta de atenção e planejamento nesse âmbito.

A arborização nas cidades torna-se uma necessidade para a vida de seus habitantes (MARTELLI et al. 2020; SILVA et al., 2020a), logo, os órgãos municipais precisam atentar para as ações de replanejamento e manejo, realizadas para garantir a qualidade da AU e, consequentemente, o desempenho das funções dessa vegetação. Desse modo, a baixa diversidade vegetal e até a ausência de vegetação em algumas praças públicas, como observado em Castanhal, precisam ser repensadas pelos órgãos responsáveis, uma vez que deixam de cumprir os serviços ecossistêmicos que poderiam oferecer.

Alguns trabalhos realizados no Brasil tiveram objetivos parecidos com o desta pesquisa, por exemplo, na cidade de Palmas (TO), foi realizado um levantamento botânico nas quadras residenciais urbanas, em que foram amostradas 16.294 plantas, pertencentes a 200 espécies e 47 FB (PINHEIROS et al., 2020). No município de Ampére (PR), o inventário foi realizado em 16 bairros, resultando em 1.218 indivíduos amostrados, com 49 espécies e 25 FB (SOARES; PELLIZZARO, 2019). Em Buriticupu (MA), foram catalogados 544 indivíduos distribuídos em 33 espécies e $23 \mathrm{FB}$ (SOUSA et al., 2019).

Estudos internacionais com objetivos análogos demonstraram valores elevados em comparação às pesquisas citadas acima, por exemplo, no bairro central da cidade Santiago del Estero na Argentina, foram encontrados 3.125 exemplares arbóreos, 33 espécies e 73 FB (ARIAS et al., 2020). Pereira et al. (2019) encontraram 1.414 exemplares, pertencentes a 75 espécies nas praças da cidade de Cárdenas, Venezuela. E na cidade de Resistencia, Argentina, foram identificados cerca de 6.352 indivíduos e 94 espécies (ORTIZ; LUNA, 2019). Nos dois últimos estudos citados os autores não apresentaram as FB.

Os dados desses trabalhos (nacionais e internacionais), quando comparados ao município de Castanhal, apontam que o municí- pio deste estudo está aquém no que se refere à biodiversidade em espécies, contendo ainda poucas unidades em suas praças. Isso demostra que é preciso dar maior atenção para a qualidade e quantidade arbórea urbana em Castanhal. Adicionalmente, é importante ressaltar que as diferenças quantitativas desses estudos estão atreladas a questões específicas de cada local, como cultura, economia e política.

Em relação à origem, das 11 espécies encontradas no presente estudo, $27,27 \%$ são espécies nativas (n) e $72,73 \%$ são consideradas espécies exóticas (e). As exóticas encontradas são naturais da Ásia (75\%), América Central (12,5\%) e África (12,5\%). Castanhal segue um modelo de AU parecido com o de muitas cidades brasileiras, que prioriza espécies exóticas em detrimento das nativas, negligenciando e ignorando os prejuízos que essa escolha pode gerar.

As espécies exóticas, mesmo sendo amplamente utilizadas em espaços urbanos, podem causar inúmeros problemas ecológicos. São classificadas em: (1) introduzidas, que são plantas transportadas de fora do local de origem para outro; (2) naturalizadas, que são espécies que superaram barreiras reprodutivas; e (3) ervas daninhas, que são as introduzidas com potencial para produzir descendentes férteis longe do seu ambiente natural (BANERJEE; DEWANJI, 2017).

No entanto, Esteves e Correia (2018, p. 162) afirmam que "em face da megadiversidade de espécies arbóreas brasileiras, a arborização urbana no país deve valorizar a flora local, como forma de difundi-la entre a população, aumentar a capacidade de suporte para a fauna urbana e contribuir para a conservação da biodiversidade". Ainda, o uso dessas espécies contribui para relações ecológicas com polinizadores e dispersores de sementes, essenciais para conservação da diversidade ecológica. Destaca-se que o declínio na biodiversidade da silvicultura urbana pode tornar esses sistemas suscetíveis à vulnerabilidade de extremos como pragas, patógenos, espécies invasoras e outros fatores de perturbação (KAISER-BUNBURY et al., 2017).

Aconselha-se que seja priorizado o uso de espécies nativas na silvicultura urbana, pois elas protegem o estabelecimento e manutenção da fauna nativa, impedindo a invasão de áreas naturais por 

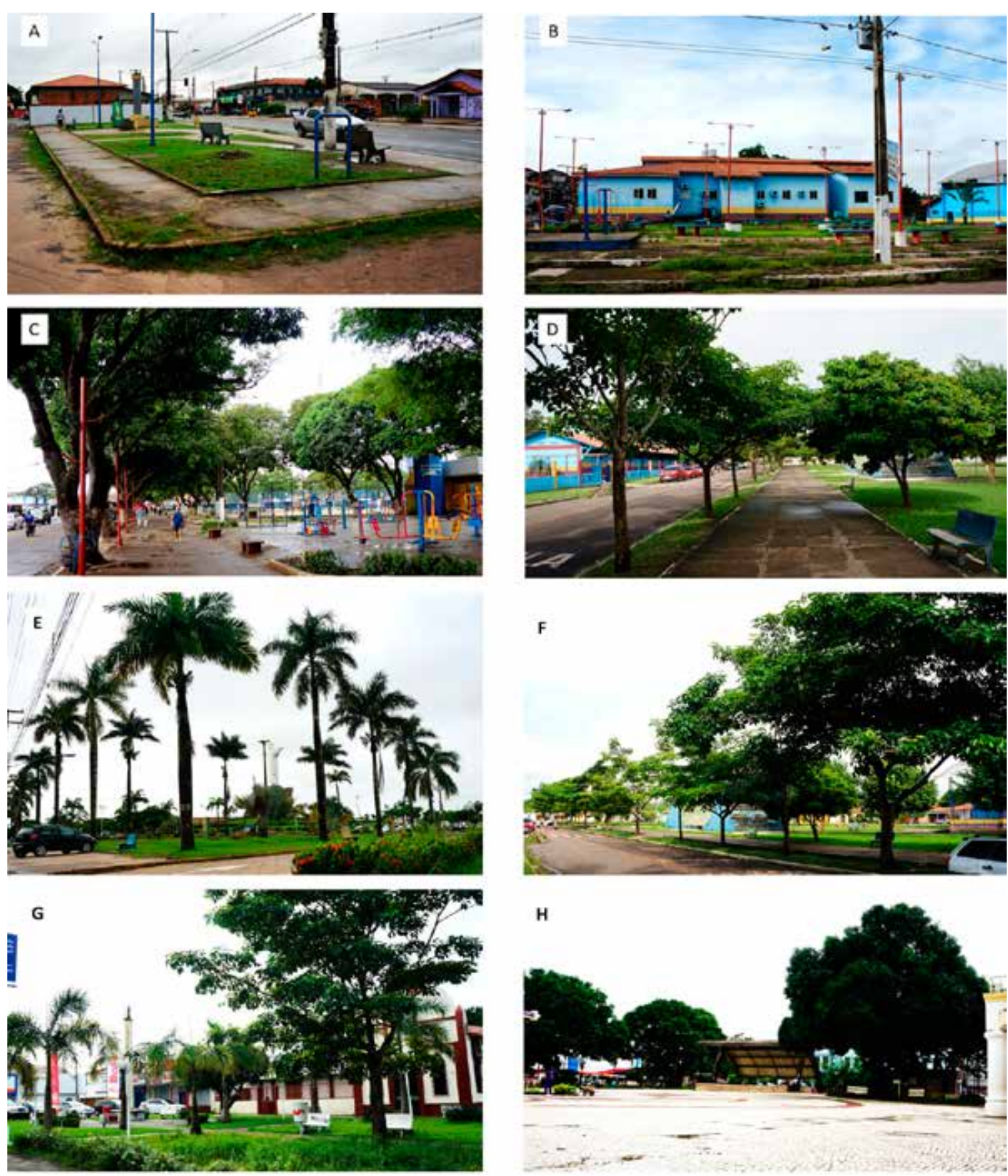

Figura 3 - Representação das praças sem arborização (A; B) em contraste com as praças que tiveram maior representação dos indivíduos identificados (C; D; E; F; G e H), por Larisse Gonçalves, 2017. 
exóticas, além de proporcionarem uma identidade arbórea para a cidade, que serve como atrativo ao turismo e fomento à economia local (GONÇALVES et al., 2018). Ademais, para que a conscientização da população e dos órgãos responsáveis pela manutenção dessas áreas verdes seja evidente, faltam muitos cuidados como: "técnicos capacitados que orientem sobre um plantio correto, a escolha das espécies, poda de formação, utilização de tutores, grade de proteção, irrigação em período de estiagem e adubação" (GONÇALVES et al., 2018, p. 132). Ressalta-se que a implementação de biodiversidade nativa arbórea na cidade de Castanhal estimularia os benefícios citados acima.

O Plano Diretor Participativo (PDP, 2007) de Castanhal tem como pauta a promoção, a preservação e o planejamento da qualidade da paisagem e espaços públicos, por meio da $A U$ pública existente, que ajuda a destacar a imagem de um elemento simbólico, a identidade cultural, a qualidade de vida urbana, o turismo e a economia da região. No entanto, os resultados demonstram a desatenção dos entes municipais e a necessidade de maiores esforços para fomentar, de fato, ações de replanejamento e manejo, para garantir a qualidade da $\mathrm{AU}$ e, consequentemente, o desempenho das funções dessa vegetação.

Em uma pesquisa que investigou a ocorrência de espécies arbóreas em 17 espaços verdes urbanos na cidade de Recife em Pernambuco, foi demonstrado que $49,1 \%$ eram nativas e $50,9 \%$ exóticas. Entretanto, ao considerar a origem do bioma estudado (Mata Atlântica), os valores evidenciaram que $80,5 \%$ dos exemplares não ocorriam na floresta atlântica do Nordeste brasileiro. Fator esse que aponta relações negativas com espécies nativas, como a maior capacidade reprodutiva, aumento da capacidade de colonização e o risco de invasão, sendo marcadas como ameaças à conservação do ecossistema. Portanto, identificar o potencial invasivo antes de sua propagação e estabelecimento na paisagem é extremamente importante para a conservação das plantas nativas (SILVA et al., 2020b).

No entanto, não se deve ser austero e excluir espécies exóticas de projetos de $\mathrm{AU}$, porém é essencial compreender que, na elaboração de ambientes verdes, além de cumprir um papel estético, eles também precisam ser funcionais, gerando serviços ambientais e in- terações com a fauna nativa, o que muitas vezes o uso de espécies exóticas põe em risco (PAIVA, 2009).

Em Bolonha, na Espanha, uma pesquisa encontrou cerca de $57 \%$ de exóticas e $43 \%$ nativas, em que das exóticas cerca de $43 \%$ são originárias da América do Norte e do Sul, $42 \%$ da Ásia, 7\% da África, 4\% de outros países da Europa Ocidental e Oriental e 1\% da Austrália (SALINITRO et al., 2018). Lorenzi (2002) assegura que o Brasil possui a flora arbórea mais diversificada do mundo, com centenas de espécies de grande beleza paisagística, todavia, a maior parte das plantas arbóreas usadas na AU são espécies exóticas. Os ambientes urbanos também são hotspots ${ }^{1}$ de espécies raras, muitas das quais com distribuição parcial ou majoritariamente nas cidades (SALINITRO et al., 2018).

A partir da análise dos dados obtidos com os de outros estudos, percebe-se que outros países utilizam da biodiversidade brasileira para o seu planejamento arbóreo urbano e no Brasil são introduzidas espécies de muitos outros continentes. Isso pode estar atrelado à falta de conhecimento técnico dos gestores responsáveis e à não valorização da biodiversidade arbórea nativa com potencial paisagístico. Gonçalves et al. (2018) comentam que a AU possui um histórico de ser praticada de forma empírica e, poucas vezes, é orientada por um contexto técnico-científico.

A Mangifera indica L. (mangueira) $(34,7 \%$ do total de indivíduos amostrados) e o Ficus benjamina L. (fícus) $(22,7 \%)$ apresentaram maior incidência, correspondendo juntos a mais de $50 \%$ do total de plantas, expressando baixa heterogeneidade. Em Buriticupu (MA), as espécies mais encontradas foram o Licania tomentosa (oiti) $(34,74 \%)$ e o Ficus benjamina L. (ficus) $(18,01 \%)$ (SOUSA et al., 2019), que representaram mais da metade da arborização, resultados parecidos com os de Castanhal. Destaca-se que a baixa variabilidade na distribuição quantitativa de espécies é inadequada, pois, de acordo com Santamour Júnior (2002), não é recomendado que se utilize mais de $30 \%$ de espécies de uma mesma FB em uma única área pública urbana. Ademais, Milano (1984) recomenda que cada espécie não ultrapasse $15 \%$ do total de indivíduos. Os dois autores

\footnotetext{
1 Hotspot de biodiversidade é uma região biogeográfica que é simultaneamente uma
} reserva de biodiversidade, que pode estar ameaçada de destruição. 
consideram os riscos de pragas e doenças, que podem comprometer a longevidade das espécies.

Em relação às FBs, foram encontradas as seguintes: Chrysobalanaceae, Combretaceae, Bignoniaceae, Leguminosae - Caesalpinioideae, Moraceae, Anacardiaceae, Arecaceae e Myrtaceae. A única família com duas espécies diferentes foi a Arecaceae, representada por 55 indivíduos. Em Boa Vista (RR), Neto et al. (2016) demonstraram que as espécies mais frequentes estavam distribuídas em sete FB, que contemplavam 96,3\% da população, sendo estas Myrtaceae, Chrysobalanaceae, Moraceae, Bombacaceae, Anacardiaceae, Fabaceae e Bignoniaceae, demonstrando a presença de biodiversidade na sua composição.

Geralmente, existe uma expressiva participação de plantas da família Fabaceae na arborização das praças urbanas brasileiras (LEMES et al., 2009). Confirma-se essa existência na cidade de Castanhal, todavia, elas não estão presentes de maneira significativa e a maior incidência identificada foi a da FB Anacardiaceae. Na cidade de Macapá, onde foi realizado um estudo equivalente, os resultados foram parecidos, demonstrando que as espécies dispostas em áreas urbanas se concentram nessa família (GOMES et al., 2016). Essa diferença entre predominância de espécies pode estar relacionada à região, pois no Norte, a mangueira (Anacardiaceae) é uma espécie frequentemente presente na $\mathrm{AU}$.

Em Belém do Pará, nas ruas centrais e praças foram implantadas mangueiras que, além de harmonizarem o clima, proporcionam apreço da população local por conta dos seus frutos, essa espécie é uma marca da cidade, que é conhecida como Cidade das Mangueiras. Dando uma atenção especial a essa espécie, por conta da simbologia em torno do seu uso na Região Norte, Pinto e Ferreira (1999) frisam que é uma exótica originária da Ásia, mas amplamente cultivada nos países tropicais e até mesmo subtropicais. Foi introduzida no Brasil no início do século XVIII pelos portugueses, tornando-se uma das principais culturas do país.

No entanto, Carvalho et al. (2010) e Mascaró e Mascaró (2005) discutem em suas pesquisas que, embora a frutificação da mangueira possa representar um efeito ornamental e ofertar atrativos para a fauna local, oferecendo muitos benefícios ao meio ambiente, quando plantada em ruas centrais, pode acarretar problemas ao deixar seus frutos caírem sobre os transeuntes e motoristas. Outro fator que deve ser levado em consideração é que esses frutos atraem morcegos, que podem ser vetores da raiva (TOSCAN et al., 2010).

É de grande valia comentar que em Belém (PA) a composição da silvicultura urbana sempre esteve conexa às dinâmicas socioeconômicas. Nas áreas centrais da capital paraense, esses sistemas possuem grande porte de forma estratégica, demarcando paisagisticamente territórios elitizados e de interesses turísticos, delineados por negócios de imobiliárias e espelhando a valorização e distinção socioeconômica (LIMA et al., 2020). Os autores comentam ainda que, na periferia da cidade, a AU não é planejada, sendo pontual e arbustiva, dificultando a criação de espaços socioambientais adequados, com ocorrência disforme, que potencializa problemas de saúde pública, lazer e incompatibilidade com infraestruturas urbanas.

Salienta-se que esses fatores estão diretamente atrelados ao processo de desenvolvimento endógeno, pois é necessário dispor de equidade social, integrando meios que contribuam para que os diferentes grupos tenham equivalência na busca por qualidade de vida, como direitos mínimos que se conectem a fatores culturais, ambientais e políticos, em função da mitigação de desigualdades (RIZZOTTO; BORTOLLO, 2011).

Ainda, autores como Duarte et al. (2018, p. 337) inferem que o maior acesso a espaços verdes é proporcional à renda média e às condições da moradia, e, acerca do perfil de valorização da AU no Brasil, comentam:

A falta de valorização dada à arborização urbana no planejamento urbano no Brasil tem suas raízes históricas no modelo urbanístico da colonização portuguesa. Atualmente, sua desvalorização é decorrente de fatores sociais, econômicos e até mesmo pela falta de conhecimento sobre os benefícios e importância das árvores no meio urbano. Neste cenário, apenas algumas poucas cidades se destacam pela arborização urbana bem planejada, enquanto a maior parte 
das cidades brasileiras nem sequer possuem leis específicas ou corpo técnico especializado para o planejamento, execução e fiscalização da arborização urbana.

Cabe aqui a reflexão de que a silvicultura urbana possui uma potência indiscutível na qualidade de vida das populações, demonstrando que ela ressalta questões além da sua atuação funcional no meio ambiente. A falta de infraestrutura urbana, especialmente para a população mais vulnerável, é um catalizador da intensificação de desigualdade social. Diante dessa colocação, Duarte et al. (2018, p. 328) afirmam que "a expansão das áreas urbanas deve valorizar e incrementar a $\mathrm{AU}$, como forma de compensação da perda de qualidade ambiental ocorrida no processo de produção do espaço", visando minimizar a segregação socioespacial.

Essa relação entre a desigualdade e a localização de espaços verdes nas cidades pode ser confirmada também em outros países como, por exemplo, no Noroeste do Pacífico, no Oeste das Montanhas Cascade (EUA), onde os bairros urbanos com maior nível socioeconômico tendem a ser mais arborizados. O estudo afirma que a região que possui menor disparidade socioeconômica protuberante entre os habitantes é propensa à maior arborização e biodiversidade (MILLS et al., 2016).

Para o sucesso de ambientes com AU são necessários vários quesitos, como: plano de manejo em toda a cidade, funcionários da cidade, ferramentas de avaliação, proteção das árvores existentes, seleção de espécies e espaço, padrões para o cuidado das árvores, segurança do cidadão e reciclagem. Consequentemente, a abordagem contemporânea de planejamento e manejo nas florestas urbanas demanda que muitos grupos de profissionais e especialistas atuem em harmonia, quiçá, com a participação da população local (KÖSE, 2020).

Castanhal necessita de uma implantação de medidas que fortaleçam a $A U$, que sejam praticadas com espécies nativas, pois a maioria dos indivíduos encontrados nos ambientes públicos analisados foram árvores exóticas, que podem apresentar problemas com pragas e doenças, mesmo que algumas se adaptem bem ao ambiente da cidade. Uma maior diversidade possibilita maior resistência das espécies ao ataque de agentes fitopatogênicos e pragas e contribui para a manutenção da avifauna local e para a conservação das espécies e da biodiversidade.

Vale ressaltar que a equipe participante da pesquisa procurou a Secretaria Municipal de Meio Ambiente (SEMMA) de Castanhal a fim de compreender os manejos existentes e a execução do plano gestor que orienta a manutenção da arborização viária, porém, a prefeitura não possui nenhum plano de manejo, como: poda, plantio, adubação, secção de raízes, avaliação de árvores de risco, controle sanitário de árvores etc. Também não há registro das espécies presentes nas praças, demonstrando que os plantios feitos foram aleatórios e sem uma recomendação técnica prévia a respeito da distribuição de espécies nesses ambientes públicos, fortalecendo a ideia de que existe negligência em relação a esses locais e em relação aos aspectos legais voltados à arborização urbana.

A cidade de Castanhal necessita homogeneizar a distribuição das espécies para manter esse patrimônio arbóreo sadio, prolongando a disponibilidade desses espaços para a população e melhorando a qualidade dos mesmos. Outrossim, uma forma de estimular a melhoria da AU é aumentar a conscientização da população sobre a importância desses ambientes para ajudar a garantir o apoio de gestores públicos locais e outros tomadores de decisão.

\section{Conclusõos}

Este estudo demonstrou que há pouca diversidade vegetal nas praças de Castanhal, especialmente quando os dados focalizaram as espécies arbóreas nativas, que representam $27,27 \%$ do total amostrado, a Mangifera indica L. (34,7\%) e o Ficus benjamina L. (22,7\%), espécies exóticas, apresentaram maior incidência, com mais de $50 \%$ do total de espécies. Esses dados demonstram que não existe prioridade em utilizar as espécies nativas, como é recomendado na literatura, fator que pode prejudicar a integridade ecológica, social e econômica.

Conclui-se, também, que as entidades responsáveis devem introduzir novas espécies, sobretudo, nas praças com nenhuma cobertura 
vegetal, dando preferência a plantas nativas da região. Adicionalmente, essas ações requererão maior envolvimento da gestão local para garantir efetividade e êxito na implementação da arborização urbana no município.

\section{ReferênCIAS BibliográficAS}

ARIAS, María Eugenia.: CELEMÍN , Juan Pablo.; FUSTER, Andrea Alejandra. Arbolado público en el barrio Centro, ciudad de Santiago del Estero. Estado actual y conformidad con la normativa municipal. Revista Estudios Ambientales, v. 8, n. 1, 95114,2020. DOI: (https://doi.org/10.47069/estudios-ambientales.v8i1.660).

BANERJEE, Achyut Kumar; DEWANJI, Anjana. Native exotic relationships in plant communities: the role of exotic dominance in framing community composition. Ecological Research, v, 32, n. 5, p. DOI:(653-665, 2017, https://doi.org/10.1007/ s11284-017-1476-x)

BRIANEZI, Daniel.; JACOVINE, Laércio Antônio.; GONÇALVES, Wantuelfer.; ROCHA, Samuel José Silva Soares da. Avaliação da arborização no campus-sede da Universidade Federal de Viçosa. Revista da Sociedade Brasileira de Arborização Urbana. v. 8, n. 4, p. 89-106, 2013. DOI: (http://dx.doi.org/10.5380/revsbau.v8i4.66506).

CBD. SECRETARIAT OF THE CONVENTION ON BIOLOGICAL DIVERSITY. Cities and Biodiversity Outlook. Montreal: [s.n.], 2012. 64 p. Disponível em: <https://www.cbd. int/doc/health/cbo-action-policy-en.pdf>. Acesso em: 10/01/2018.

CARVALHO, José Adenilson.; NUCCI, João Carlos.; VALASKI, Simone. Inventário das árvores presentes na arborização de calçadas da porção central do bairro Santa Felicidade-Curitiba/PR. Revista da Sociedade Brasileira de Arborização Urbana Piracicaba, v. 5, n. 1, p. 126-143, 2010. DOI: (http://dx.doi.org/10.5380/revsbau. v5i1.66247)

DUARTE, Taíse Ernestina Prestes Nogueira et al. Reflexões sobre arborização urbana: desafios a serem superados para o incremento da arborização urbana no Brasil. Revista em Agronegócio e Meio Ambiente, v. 11, n. 1, p. 327-341, 2018. DOI: (http://dx.doi.org/10.17765/2176-9168.2018v11n1p327-341).

ENDRENY, Theodore A. Strategically growing the urban forest will improve ou world. Nature communications, v. 9, n. 1, p. 1-3, 2018. DOI: (https://doi.

org/10.1038/s41467-018-03622-0)

ESTEVES, Mariana Campos, CORRÊA, Rodrigo Studart Natividade da flora usada na arborização de cidades brasileiras. Paranoá: cadernos de arquitetura e urbanismo v. 22, p. 159-17, 2018. DOI: (http://dx.doi.org/10.18830/issn.1679-0944.n22.2018.11). FOOD AND AGRICULTURE ORGANIZATION OF THE UNITED NATIONS. Building green er cities: nine benefits of urban trees. 2016. Disponível em: <http://www.fao.org/ zhc/detail-events/en/c/454543/> Acesso em: 29/08/2016.

GALLO, Douglas; GUARALDO, Eliane. Arborização Urbana como Infraestrutura na constituição de uma cidade com Qualidade de Vida: potencialidades em Campo Grande/MS. Revista Nacional de Gerenciamento de Cidades, v. 5, n. 31, 2017 DOI:(http://dx.doi.org/10.17271/2318847253120171577).

GONÇALVES, Larisse Medeiros et al. Arborização Urbana: a Importância do seu Planejamento para Qualidade de Vida nas Cidades. Ensaios e Ciência, v. 22, n. 2, p. 128-136, 2018. DOI: (https://doi.org/10.17921/1415-6938.2018v22n2p128-136).
GOMES, Ediellen Mayara Corrêa et al. Análise quali-quantitativa da arborização de uma praça urbana do Norte do Brasil. Nativa, Sinop, v. 4, n. 3, p. 179-186, 2016. Disponível em: <https://core.ac.uk/reader/229930314>. Acesso em: 20/08/2016.

HAN, Xiuyan; SUN, Tao; CAO, Tianyi. Study on landscape quality assessment of urban forest parks: Take Nanjing Zijinshan National forest Park as an example. Ecological Indicators, v. 120, p. 106902, 2021. DOI:(https://doi.org/10.1016/j.ecolind.2020.106902).

INSTITUTO BRASILEIRO DE GEOGRAFIA E ESTATÍTICA. Censo Demográfico 2020. Disponível em: <https://www.ibge.gov.br/apps/populacao/projecao/index.html?utm_ source $=$ portal\&utm_medium $=$ popclock\&utm_campaign $=$ novo_popclock $>$. Acesso em: 21/01/2020

KAISER-BUNBURY, Christopher N. et al. Ecosystem restoration strengthens pollination network resilience and function. Nature, v. 542, n. 7640 , p. 223-227, 2017. DOI: (https://doi.org/10.1038/nature21071)

KÖSE, Murat. Factors Affecting the Planning and Management of Urban Forests: A Case Study of Istanbul. Urban Forestry \& Urban Greening, p. 126739, 2020 DOI:(https://doi.org/10.1016/j.ufug.2020.126739).

LACY, Peter de; SHACKLETON, Charlie. Woody plant species richness, composition and structure in urban sacred sites, Grahamstown, South Africa. Urban Ecosystems, v. 20, n. 5, p. 1169-1179, 2017. Disponível em: <https://link.springer.com/article/10.1007/s11252-017-0669-y>. Acesso em: 05/08/2020.

LEMES, Pedro Guilherme et al. Bauhinia variegata (Fabaceae) dieback caused by Praelongorthezia praelonga (Hemiptera: Ortheziidae). Florida Entomologist, v. 102 n. 3, p. 630-634, 2019. DOI:(https://doi.org/10.1653/024.102.0337).

LIMA, Gabriel Villas Boas de Amorim. et al. O direito à cidade arborizada: a arborização urbana como indicador da segregação socioeconômica em Belém do Pará. Revista da Sociedade Brasileira de Arborização Urbana. Curitiba -PR, v. 15, n. 1, p. 79-96, 2020. Disponível em: <https://revistas.ufpr.br/revsbau/article/download/69694/ pdf > Acesso em: 01/08/2020

LORENZI, Harri. Árvores brasileiras: Manual de Identificação e Cultivo de Plantas Arbóreas do Brasil. 4ed. Nova Odessa, SP: Instituto Plantarum, 2002.

LORENZI, Harri. Plantas para jardim no Brasil: herbáceas, arbustivas trepadeiras. Nova Odessa, SP: Instituto Plantarum. 2013.

LORENZI, Harri; SOUZA, Hermes Moreira de Sousa. Plantas ornamentais no Brasil: arbustivas, herbáceas e trepadeiras. $3^{\text {a }}$ ed. Nova Odessa, SP: Instituto Platarum. 2001.

LOURDES, Karen et al. A Review of Urban Ecosystem Services Research in Southeas Asia. Land, v. 10, n. 1, p. 40, 2021. DOI: (https://doi.org/10.3390/land10010040).

MADUEIRA, Helena. Infra-estrutura verde na paisagem urbana contemporânea: o desafio da conectividade e a oportunidade da multifuncionalidade. Geografia: Revista da Faculdade de Letras da Universidade do Porto, n. 1, 2012. Disponível em: <http://193.137.34.194/index.php/geografia/article/view/10>. Acesso em: 17/02/2021. MASCARÓ, Lucia; MASCARÓ, Juan. Vegetação Urbana. Porto Alegre: Ed. Mais Quatro, 2005.

MARTINS-DA-SILVA, Regina Célia Viana. Coleta e identificação de espécimes botânicos. Embrapa Amazônia Oriental-Documentos (INFOTECA-E), 2002. Disponível em: <https://www.infoteca.cnptia.embrapa.br/bitstream/doc/405766/1/OrientalDoc143. PDF>. Acesso em: 10/06/2016. 
MARTELLI, Anderson et al. Sergio Fernando. Ação ambiental sobre a importância da arborização urbana com crianças da educação inicial do município de Itapira-SP. Brazilian Journal of Development, Curitiba, v. 6, n. 4, p. 17108-17119, 2020. DOI:(https:// oi.org/10.34117/bjdv6n4-035).

MILANO, Miguel S Serediuk. Avaliação e análise da arborização de ruas de Curitiba-PR. 1984. 130 f. 1984. Tese de Doutorado. Dissertação (Mestrado em Engenharia Florestal), Setor de Ciências Agrárias, Universidade Federal do Paraná, Curitiba. Disponível em: <https://acervodigital.ufpr.br/bitstream/handle/1884/40695/D\%20-\%20MIGUEL\%20 SEREDIUK\%20MILANO.pdf>. Acesso em: 06/08/2020.

MILLS, John R.; CUNNINGHAM, Patrick; DONOVAN, Geoffrey H. Urban forests and social inequality in the Pacific Northwest. Urban forestry \& urban greening, v. 16, p. $188-$ 196, 2016. DOI: (https://doi.org/10.1016/j.ufug.2016.02.011).

NASCIMENTO, Lorena Alves Carvalho; SHANDAS, Vivek. Integrating Diverse Perspective for Managing Neighborhood Trees and Urban Ecosystem Services in Portland, OR (US). Land, v. 10, n. 1, p. 48, 2021. DOI:( https://doi.org/10.3390/land10010048).

NETO, Everaldo Marques Lima et al. Análise da composição florística de Boa Vista-RR: subsídio para a gestão da arborização de ruas. Revista da Sociedade Brasileira de Arborização Urbana, v. 11, n. 1, p. 58-72, 2016. DOI: (http://dx.doi.org/10.5380/revsbau.v11i1.63390)

ORTIZ, Nicolás Leandro.; LUNA, Claudia Verónica. Diversidad e indicadores de vegetación del arbolado urbano en la ciudad de Resistencia, Chaco-Argentina. Revista Facultad de Agronomía, v. 39, n. 2, p. 54-68, 2019. Disponível em: < http://agronomiayambiente.agro.uba.ar/index.php/AyA/article/view/97/93> Acesso em: 01/08/2020.

PEREIRA, E.; FLORES, D.; CASTILLO, M. Caracterización de la flora leñosa de los principales espacios verdes urbanos de la parroquia Táriba, municipio Cárdenas, Estado Táchira. Venezuela. Revista de Ciencias Forestales, Quebracho, v. 27, n. 2, p. $108-104,2019$ Disponível em: <https://fff.unse.edu.ar/index.php/quebracho-revista-numeros-publicados/> Acesso em: 21/10/2020

PAIVA, Ary Vieira de. Aspectos da arborização urbana do Centro de Cosmópolis-SP. Revista da Sociedade Brasileira de Arborização Urbana, Piracicaba - SP, v. 4, n. 4, p. 17-31, 2009. DOI:(http://dx.doi.org/10.5380/revsbau.v4i4.66446).

PINHEIRO, Renato Torres; MARCELINO, Dianes Gomes; MOURA, Dieyson Rodrigues. Composição e diversidade arbórea nas quadras urbanizadas de Palmas, Tocantins. Ciência Florestal, v. 30, n .2, p. 565-582, 2020. DOI:( https://doi.org/10.5902/1980509837601). PINTO, Alberto Carlos de Queiróz; FERREIRA, Francisco Ricardo. Melhoramento genético recursos genéticos e melhoramento da mangueira no Brasil. Embrapa Sem -Árido/Brasília-DF, Embrapa Recursos Genéticos e Biotecnologia, Petrolina, PE. 1999. Disponível em: <http://www.ceinfo.cnpat.embrapa.br/arquivos/artigo_2568.pdf>. Acesso em: 15/02/2017

PLANO DIRETOR PARTICIPATIVO DE CASTANHAL 2007 - 2016. Disponível em: <http:// www.sedurb.pa.gov.br/pdm/castanhal/PD_CASTANHAL.pdf >. Acessado em: 20/01/2016.

PORTO, Luis Paulo Monteiro; BRASIL, Heliana Maria Silva. Manual de Orientação Técnica da Arborização Urbana de Belém: guia para planejamento, implantação e manuten- ção da arborização em logradouros públicos. Belém: Universidade Federal Rural da Amazônia, 2013. Disponível em: <http://ww3.belem.pa.gov.br/www/wp-content/uploads/ Manual-de-Arboriza\%C3\%A7\%C3\%A3o-de-Bel\%C3\%A9m.pdf>. Acesso em: 23/02/2021.

ROMAN, Lara et al. Human and biophysical legacies shape contemporary urban forests: A literature synthesis. Urban Forestry \& Urban Greening, v. 31, p. 157-168, 2018 DOI: (https://doi.org/10.1016/j.ufug.2018.03.004)

RIZZOTTO, Maria Lucia Frizon; BORTOLOTO, Claudimara. O conceito de equidade no desenho de políticas sociais: pressupostos políticos e ideológicos da proposta de desenvolvimento da CEPAL. Interface-Comunicação, Saúde, Educação, v. 15, p. 793-804 2011. DOI: (https://doi.org/10.1590/S1414-32832011000300014).

SALINITRO, Mirko et al. Floristic diversity in different urban ecological niches of a southern European city. Scientific reports, v. 8, n. 1, p. 1-10, 2018. DOI: (https://doi org/10.1007/s11252-017-0669-y).

SANTAMOUR JÚNIOR, F. S. Trees for urban planting: diversity unifomuty, and com mon sense. Washington: US National Arboretum. Agriculture Research Service, 2002. Disponível em: <https://pdfs.semanticscholar.org/26a2/4c5361ce6d6e618a9fa307c4a34a3169e309.pdf>. Acesso em: 06/08/2020.

SILVA, Ivanessa dos Santos. et al. Percepção sobre a arborização da praça centenário em Maceió, AL. Brazilian Journal of Development, Curitiba, v. 6, n. 6, p. 37756 37766. 2020a. DOI:( http://10.34117/bjdv6n6-347).

SILVA, Jéssica Luiza Souza. et al. High richness of exotic trees in tropical urban green spaces: Reproductive systems, fruiting and associated risks to native species. Urban Forestry \& Urban Greening, v. 50, p. 126659, 2020b. DOI:(https://doi.org/10.1016/j. ufug.2020.126659).

SIRVINSKAS, L.P. Arborização urbana e meio ambiente: aspectos jurídicos. Revista do Instituto de Pesquisas e Estudos, p. 263-276, 2000. Disponível em: <http://www. mpsp.mp.br/portal/page/portal/documentacao_e_divulgacao/doc_publicacao_divulgacao/ doc_gra_dout_crim/crime\%2012.pdf>. Acesso em:06/08/2020.

SOARES, Jeandra; PELLIZZARO, Luciana. Inventário da Arborização Urbana do município de Ampére (Paraná-Brasil). Revista Brasileira de Meio Ambiente, v. 5, n. 1, 2019. DOI: (http://doi.org/10.5281/zenodo.2654381).

SOUSA, Lidia Aguiar et al. Levantamento quali-quantitativo da arborização urbana no município de Buriticupu, MA. Revista da Sociedade Brasileira de Arborização Urbana, Curitiba, v. 14, n. 1, p. 42-52, 2019. DOI: (http://dx.doi.org/10.5380/revsbau. v14i1.65372).

TOSCAN, Maria Angélica Gonçalves et al. Inventário e análise da arborização do Bairro Vila Yolanda, do município de Foz do Iguaçu-PR. Revista da Sociedade Brasileira de Arborização Urbana v. 5, n. 3, p. 165-184, 2010. DOl:( http://dx doi.org/10.5380/revsbau.v5i3.66311).

ZHI-YING, Han; YEO-CHANG, Youn. Beijing Resident's Preferences of Ecosystem Services of Urban Forests. Forests, v. 12, n. 1, p. 14, 2021. DOI:( https://doi.org/10.3390/ f12010014). 
Larisse Medeiros Gonçalves

Universidade Tecnológica Federal do Paraná (UTFPR)

Campus Pato Branco, Via do Conhecimento, km 1- CEP 85.503-390,

Caixa Postal 571- CEP 85.502-970 Pato Branco, Paraná, Brasil

https://orcid.org/0000-0002-8546-3244

larisse@alunos.utpfr.edu.br

Luana Santos dos Santos

Universidade Tecnológica Federal do Paraná (UTFPR)

Campus Pato Branco, Via do Conhecimento, km 1- CEP 85.503-390,

Caixa Postal 571- CEP 85.502-970 Pato Branco, Paraná, Brasil

https://orcid.org/0000-0001-5771-9882

luana.1995@alunos.UTFPR.edu.br

Pedro Henrique da Silva

Universidade Tecnológica Federal do Paraná (UTFPR)

Campus Pato Branco, Via do Conhecimento, km 1- CEP 85.503-390,

Caixa Postal 571- CEP 85.502-970 Pato Branco, Paraná, Brasil

https://orcid.org/0000-0002-4951-4235

pedromonteiro@alunos.utfpr.edu.br

Louise Ferreira Rosal

Instituto Federal do Pará (IFPA)- Campus Castanhal

BR-316, km 63, s/nº - Saudade.

Caixa Postal 1611 - CEP 68740-970

Castanhal, Pará, Brasil.

https://orcid.org/0000-0001-5514-1490

louise.rosal@ifpa.edu.br

Nota do Editor

Data de Submissão: 23/10/2020

Data de Aprovação: 27/04/2021

Revisão: RMO 